\title{
Research on the Practice of Organizational Innovation Management in Higher Vocational Colleges
}

\author{
Dong Li \\ Xi’an Aeronautical Polytechnic Institute \\ Xi’an, China
}

\begin{abstract}
The improvement of school management is a systematic and continuous effort to change the conditions of learning and other related internal conditions in one or more schools so as to achieve more effective educational goals. As a complex change, the essence of school improvement is organizational change at the school level, and continuity is the main feature. China's higher vocational colleges have been developing very fast in recent years. The innovation of organizational management can support the development of schools.
\end{abstract}

Keywords-innovation; Higher Vocational Colleges; Continuous improvement; PDCA

\section{INTRODUCTION}

Today's world is a world with a short change cycle. Many organizations must constantly innovate management. Schools and enterprises are similar in some aspects. They all need to improve their organizational vitality and get better development opportunities in continuous reform and innovation. Xi'an Aeronautical Polytechnic Institute (XAPI), a general, full-time public higher polytechnic educational institute that was approved by the Ministry of Education and affiliated to Shaanxi Department of Education, was founded in 1958. It is one of the one hundred key state-building model higher vocational institutions. It is situated in Chinese celebrated aircraft city- Yangling, Xi'an, which is honored as Chinese Seattle, near China Aviation Industrial Base.

Up to now, XAPI possesses more than 10,000 full-time students with total area of 131 acres. There are 8 departments covering 42 majors such as aviation equipment maintenance, mechatronics, electronic information technology, and air service, etc. There are 77 labs, 18 training bases including 4 key provincial training bases, 209 outside training base relying on the airline industry. It also has the biggest aviation science and technology museum in northwest of China, key NC training base which is supported by Chinese governmentand CAIB Training school. At present, XAPI possesses 7 state model majors, 8 provincial key majors, 2 national model curricula and18 provincial model curricula.

XAPI focuses on introducing high-quality foreign educational resources and establishing close relationship with international colleges, and cooperates with Singapore, Germany and other more than 10 colleges or educational institutions from five countries successively. XAPI has built cooperative relationship with university of Arkansas, Singapore Polytechnic and Nangyang Polytechnic University.

\section{DESCRIPTION OF ORGANIZATIONAL INNOVATION LEVEL}

'Continuous improvement (CI) is a widely-used phrase which has taken on a variety of meanings. And CI can be considered as an example of what many strategy theorists call dynamic capability [1]. For many people it is synonymous with 'innovation', which means the continual quest to make things better in products, processes, customer service, etc. For others, it is a core value which lies at the heart of organizational renewal programmes like total quality management. For others it implies a preoccupation with sustained incremental change and with attention to the detail of waste reduction and quality improvement' [2]

The eight key abilities of the critical behavior for the strategic development proposed by Bessant(2003) are Understanding CI, Strategy Deployment, Leading CI, and Participation in CI, Consistency in CI, Cross Boundary CI, Sharing and Capturing Learning, Continuous Improvement of CI. According to the actual situation of the school, the core competitiveness index of Xi'an Aerotechnical Polytechnic College is relatively high, almost 3 for each, and only 'participation in CI' and 'Continuous Improvement of CI.' (key abilities 4 and 8) are relatively low. The analysis result is satisfactory, which shows the continuous improvement plans of the school to produce good results since 2016. The work of the school formed a mechanism of normalization with automatic and sustainable development making full use of a variety of management functions in the imrpoved PDCA spiral . Next, I will focus on several core competencies such as Strategy Deployment, Participation in CI, Consistency in CI and Continuous Improvement of CI.

\section{CONTINUOUS IMPROVEMENT STRATEGY OF XAPI}

Organizational innovation in schools refers to the organized, planned, cyclic, systematic and overall selfrenewing process with the school as the main body, aiming at continuously improving the education quality. It should have the goal to build efficient schools, enhance the well-being of school members and improve their ability to continue improvement in this process. Logically, the strategic planning for schools' development is the starting point for continuous improvement of schools, and is the initiative, overall planning 
and design of school development. The continuous improvement of schools is to improve schools in an all-round manner, and in this process, it will inevitably bring about changes to schools' organizational system. Among these, schools' principals and teachers should play professional and cultural role in leading and promoting continuous improvement of schools based on evidence. The managers need to examine in an effort to make their companies more innovative [3] Campus culture should also be built based on evident continuous improvement in order to enhance schools' ability in continuous improvement. Schools can reform schools' organization through the organization structure, the reorganization of organizational structure and the construction of non-administrative organization. The assessment of continuous improvement in schools is a formative selfassessment that accompanies with continuous improvement. 'In many companies, people are told to be innovative, but they are not given the processes and tools they need to be successful [4].

In accordance with the school's strategic planning (20162020) and on the basis of the reality and characteristics, it should orient towards problems and demands, adhere to interior priorities, combine internal with external aspects, and stick to the comprehensive diagnostic reform In addition, it should focus on the construction, and establish a modern concept led by the quality culture. Based on the establishment of "objective and standardized and well-designed organization with diagnostic and innovative improvement as its core, it should set up the data collection and management platform on the basis of talents training status. After 3-5 years of efforts, we establish a complete and relatively independent self-quality assurance mechanism from five dimensions: decision-making, quality production, resource construction, support services and supervision and control We build six horizontal levels of school, colleges, majors, courses, teachers and studentsto strengthen the quality dependence at all levels of school management systems Furthermore, we form a networked fullcovered internal quality assurance system that is in line with the school's actual development, embody the school characteristics, ensure the quality, adapt to the "high-quality vocational colleges" and "double first" construction demands and have a strong warning function and incentive function.

\section{EXAMPLES OF ORgANIZATIONA L CONTINUAL IMPROVEMENT}

'In developing CI capability, organizations need to move to a level of development in which strategic goals are communicated and deployed and where improvement activity is guided by a process of monitoring and measurement against these strategic objectives'[5].

\section{A. Participation in CI}

\section{$>$ Target}

By analyzing my school, the core competency rating is level 2, which is a low score. It shows that the school has a problem solving cycle, that employees have received training in basic cycles and tools, and that in the process of improvement, a major approach - such as teamwork is used. My goal is to increase this core competency level to level 3 through the implementation of the improvement strategy.
Level 3 participation requires that "Problem-solving cycle used regularly to work on problems focuses on key drivers. People use a cycle and a toolbox of different aids to help them. Teams are built to work on strategic problems, which may go beyond section to department or level with multiple approaches-e.g. teams plus individual mechanisms[6].

\section{$>$ Strategy}

In order to achieve the level 3 goal, the school should strive to improve the cycle and tool portfolio in these two areas. Through previous practice, I think the PDCA cycle is a very good tool, and is very suitable for my school. The cycle was created in 1939 by Walter A. She whart, which is one of the earliest continuous improvement process models. Most of the models of continuous improvement seen in the business management and education literature today are variants of it. In 2016, the school required each department to work out a plan for improvement, and I hope to establish a relatively complete quality assurance system through this work, so as to ensure the overall innovation and development of the school.

\section{$>$ Resources and risk}

At present, as far as most of the staff is concerned, they do not know much about the PDCA cycleOnly a few employees fully understand the solution to the problem, which is the evaluation of the core competence of the low level of the direct cause.

The school should strengthen the training of the staff, invite experts of management for teaching we should improve learning process , make full use of the PDCA cycle, from the training object and content on the planand from the training mode and training time, is ready to implement Cong Pei training effect to the examination, and make improvement from training the problem of feedback. Employees are required to implement the improvement plans made by various departments and to continue to understand the methods and functions of continuous improvement in the process of practice. Each department should also set up a group for improvement work. In addition to the study of the unified organization of the school, it is also necessary to discuss and evaluate the improvement work of the Department on a regular basis.

Such a request may increase the daily workload of employees, some of whom will not understand such practices in the process of continuous improvement, resulting in bad influence, and even affecting the enthusiasm of the people around. The leadership of each department should play a full role, with improved data to show the efficiency of the promotion, so that employees can see the effect of continuous improvement.

\section{B. Consistency in CI}

\section{$>$ Target}

By analyzing my school, the core competency rating is level 3, which is a medium score. It shows that the school is basically consistent with the overall objective of the organization in carrying out the continuous improvement work. The daily work of the staff has been closely related to continuous improvement, and people have allocated some 
time and resources to CI at work, and they also benefit from it. Our goal is to increase this core capability to level 4.

'Level 4 participation requires that "As3,and people are enabled and encouraged to change their ways of working to allow for development of CI” '[7].

\section{$>$ Strategy}

We have worked out the school's CI program, and each department has developed its own CI. in the context of its respective responsibilities. Employees of each department can get operational data for each key work each month in order to improve their work. As an important stakeholder of the school, the government will have a great impact on the school strategy, and CI system must be adjusted in a timely manner.

The school invited experts to improve the work of the assessment Modifications proposed by experts were made to meet the requirements of the various departments in a timely manner The plan must be consistent with the overall strategic planning of the school The responsibilities of leadership in each department, together with departments, are to ensure that continuous improvement work is carried out. Leaders who define group goals and control critical resources are able to create contexts and conditions that motivate followers to engage in innovative efforts to accomplish their goals'[8].

\section{$>$ Resources and risk}

It is important for teachers to prepare themselves for continual improvement. These include stimulating their enthusiasm for questioning and evaluating improvements, expanding their knowledge, developing their skills, and building collaborative work relationships. For schools, the focus of improvement efforts should be centered on students' learning and development. The school's top priority is to constantly clarify core values that ignite work enthusiasm and arouse their human response. Moreover, in the aspects of learning goal, standard and evaluation, the clarification of value is prior to the presentation of technology. The whole process of continuous improvement is based on data. Clarifying concepts and values, evaluating current activities and behavior, setting goals for progress, and so on should all be based on data collection, collation and analysis.

The process of continual improvement should be a process of improvement throughout the school. That is to say, the whole school should be involved in the process of continual improvement. Although it may be impractical for members of the school community to participate in the process of continual improvement from beginning to end, there may at least be some way for each member to plan to participate in the process. The improvement also means that in order to successfully carry out improvement activities, improvement efforts should be extended to all aspects of the school, including school organization, personnel, activities, in the interest of the students, not what departments are excluded.

Any improvement is risky and it must depend on improving the quality of the implementation to continue it. But the executive ability is restricted to the organization to a great extent. Some organizational factors play an important role in the implementation, and some factors hinder it. And they also affect the effectiveness of the school's continuous improvement and could lead to some new implementation measures. These factors include school standardization, values, culture, human capital and its development, composition and working form of staff, responsibility and compensation system, the school's financial resources, the internal management system, and leadership, which make organizational design an important step in the process of continuous improvement in schools.

\section{Continuous Improvement of CI}

\section{$>$ Target}

By analyzing my school, the core competency rating is level 2, which is a low score. It shows that schools have room for improvement in monitoring and developing continuous improvement efforts. My goal is to increase this core competency level to level 3 through the implementation of the improvement strategy.

'Level 3 participation requires that " work teams monitor and measure their own CI activities and link to a site or company CI steering/support team" [9].

\section{$>$ Strategy}

The school set up an independent department responsible for overseeing the school's continuous improvement efforts. School improvement is a process of self-assessment to detect the effectiveness of school's improvement. Contiuous process of school's improvement must be detected, and should be improved continuously and effectively to the school. We must continue to evaluate the improvement of the process, to find the basis for further improvement. The effectiveness of school can be divided into multiple dimensions, one of which is standard vertical that can increase the level of index . A measure of school improvement is raised on the basis of the original, and can reflect the improvement of the speed of the fast and slow; In addition, a school improvement degree of change index includes the depth and breadth of the development of the index change which can be used to measure the index that reflects the level of what impact, in what range.

\section{$>$ Resources and risk}

The school regularly publishes improvement reports, analyses problems in the continuous improvement work within the school, and introduces specific practices that can be provided to other departments for reference.

Due to the complexity of practical problems, in the selfevaluation of school continuous improvement, the value judgment methods often be used comprehensively. Reviewrs should not only make a factual description of the specific purpose of continuous improvement in schools, but also clarify, judge and critically reflect on the value pursuit of continuous improvement.

\section{CONCLUSION}

'Innovation has become the key goal of many organizations because of its potentially significant impact on organizational performance'[10].The continuous improvement of schools is not concerned with improvements in one aspect or a period of time. In essence, it is concerned to whether schools as an organization can maintain vitality in innovation 
and continue to grow. This process is a basic cycle composed by "plan - do - check - action", with the ultimate goal to build effective schools, improve the school members' happiness and enhance schools' ability in their own continuous improvement.

\section{REFERENCES}

[1] Teece, D., \& Pisano, G.The dynamic capabilities of firms: an introduction. Industrial \& Corporate Change, 1994, 3(3), pp.537-556.

[2] Bessant, J., \& Caffyn, S.,High-involvement innovation through continuous imp rovement. International Journal of Technology Management, 1997, 14(1), pp.7-28(22).

[3] Brown, R. Managing the "s" curves of innovation. Journal of Consumer Marketing, 1992,7(3), pp.61-72.

[4] Loewe, P., \& Dominiquini, J., Overcoming the barriers to effective innovation. Strategy \& Leadership, 2006, 34(1), pp.24-31.
[5] Bessant, J., \& Francis, D.. Developing strategic continuous improvement capability. International Journal of Operations \& Production Management, 1999,19(11), pp.1106-1119.

[6] Bessant, J.. High-involvement innovation: Building and sustaining competitive advantage through continuous change. Chichester, West Sussex: J. Wiley,2003.

[7] Bessant, J. High-involvement innovation: Building and sustaining competitive advantage through continuous change. Chichester, West Sussex: J. Wiley,2003.

[8] Lee, J, Effects of leadership and leader-member exchange on innovativeness. Journal of Managerial Psychology, 2008,23(6), pp.670687.

[9] Bessant, J., High-involvement innovation: Building and sustaining competitive advantage through continuous change. Chichester, West Sussex: J. Wiley,2003

[10] Drazin, R., Glynn, M.A. \& Kazanjian, R.K., Multilevel theorising about creativity in organizations: a sense making perspective, Academic Management Review, 1999,24(2), pp.286-307. 